\title{
Highly Sensitive Plasmonic Refractive Index Sensor using Doped Silicon: An Alternative to MIM Structures
}

Md. Omar Faruque ( $\nabla$ omarfaruque@iut-dhaka.edu )

Islamic University of Technology https://orcid.org/0000-0002-0890-0236

Rabiul Al Mahmud

Islamic University of Technology

Rakibul Hasan Sagor

Islamic University of Technology

\section{Research Article}

Keywords: High Sensitivity, Refractive Index Sensor, Doped Silicon, Alternative to MIM.

Posted Date: May 6th, 2021

DOl: https://doi.org/10.21203/rs.3.rs-382237/v1

License: (c) (1) This work is licensed under a Creative Commons Attribution 4.0 International License.

Read Full License

Version of Record: A version of this preprint was published at Plasmonics on August 6th, 2021. See the published version at https://doi.org/10.1007/s11468-021-01516-4. 


\title{
Highly Sensitive Plasmonic Refractive Index Sensor using Doped Silicon: An Alternative to MIM Structures
}

\author{
Md. Omar Faruque ${ }^{1, ~}{ }^{\text {, }}$ Rabiul Al Mahmud ${ }^{1}$, Rakibul Hasan Sagor ${ }^{1}$ \\ 1 Department of Electrical and Electronic Engineering, Islamic University of Technology \\ (IUT), Gazipur, Bangladesh. \\ * Corresponding Author (E-mail: omarfaruque@iut-dhaka.edu)
}

\begin{abstract}
:
Metal-Insulator-Metal (MIM) structures possess a number of shortcomings which include optical loss, tenability, nanofabrication challenges, chemical instability, incompatible manufacturing process etc. To overcome these shortcomings, plasmonic properties of heavily n-doped silicon are studied and found to be similar to those of conventional plasmonic metals like gold or silver. A plasmonic refractive index sensor using n-doped silicon instead of metal is designed and analyzed numerically using Finite Element Method (FEM). A maximum sensitivity of $4900 \mathrm{~nm} / \mathrm{RIU}$, which is higher than most of the MIM plasmonic refractive index (RI) sensors proposed to date, is obtained here. The RI sensor reported here, provides a significant improvement in the sensitivity of the device along with its compatibility with traditional nanoelectronics.
\end{abstract}

\section{Keywords:}

High Sensitivity, Refractive Index Sensor, Doped Silicon, Alternative to MIM.

\section{Introduction:}

Replacing slow electronic circuits with fast and still small alternative components has been one of the aims of the researchers over the last few decades. Plasmonic devices are being considered as one the potential replacements of traditional electronics due to their ability to confine electromagnetic waves to a metal-dielectric interface, allowing for nanofocusing with tremendous field enhancement utilizing the Surface Plasmon Polaritons (SPPs) [1], [2]. SPPs are produced due to the interaction of light with a metal creating an oscillation in metals electron cloud resulting to electromagnetic wave propagation [3]. Considering plasmonics as one of the potential replacements of electronics, different types of plasmonic devices are proposed and investigated both numerically and experimentally. These devices include filters [4], [5], couplers [6], [7], splitters [8]-[10], sensors [11]-[13], Bragg reflectors [14]-[16], Mach-Zehnder interferometers [17]-[19], etc. Among the plasmonic devices, plasmonic sensor is one of the most suitable devices to be integrated optical circuits considering size, performance and application requirements. Using conventional plasmonic MIM structures, different plasmonic sensors are proposed till date which includes refractive index sensors [20]-[22], temperature sensors [22]-[24], gas sensors [25], [26], biosensors [12], [27], [28] etc. Although a number of geometrical structures can be formed in order to guide SPPs, most common structures are the Insulator-Metal-Insulator (IMI) and Metal-Insulator-Metal (MIM) waveguides. Since light confinement is one of the key issues in case of plasmonic waveguides, MIM structures are more popularly used compared to IMI structures due to their ability to guide light with high confinement.

Material technology is playing a vital role in the recent development of plasmonics and plasmonic devices. SPPs are created depending mostly on the plasmonic property of a material once light is incident on it. Besides, the propagation of SPP is greatly affected by the plasmonic property. Plasmonic materials also act as the building block 
while realizing the plasmonic devices practically. Thus, in order to have a realizable plasmonic device with enhanced performance, a suitable plasmonic material is the most important thing to look for.

The optical properties of metallic films have been thoroughly investigated by Rakic et al. [29] and the modeling parameters have been found for eleven metals, including mostly used plasmonic metals, silver and gold. Though metals like gold and silver are mostly used materials in plasmonic applications due to their ability to produce and guide SPPs, they have a number of disadvantages. These disadvantages of natural metals like gold and silver limit the performances of the plasmonic devices to a great extent. One of the main disadvantages of conventional plasmonic materials is that they suffer a substantial optical loss due to the large imaginary part of the complex dielectric permittivity. At optical frequencies, loss mechanisms like interband transitions, intraband transitions, and scattering losses play a crucial role [30]. A higher amount of these three above mentioned losses makes the imaginary part of the complex permittivity larger. As a result, the plasmonic devices formed by the materials suffer a huge optical loss. Natural metals also have a fixed carrier concentration in the range of $10^{23} \mathrm{~cm}^{-3}$. Due to their high carrier concentration, the real and imaginary part of the complex dielectric permittivity is very large compared to insulators. The large value of the real part of the permittivity causes many problems in plasmonic devices which require a balanced polarization response [31]. In most of the plasmonic devices, metals are used as very thin films. The morphology of metal film is quite different from the bulk metal. Bulk metal is generally composed of larger grains compared to the much smaller grains of thin metal films. Thus, metal films grown or deposited on the substrate do not have the same optical properties as expected [32]-[34]. Also, in the case of thin-film, smaller grains cause grain-boundary scattering loss in metals [35], [36]. Optical losses in thin metal films can be three to four times more due to grain-boundary scattering loss. The optical loss also arises in ultrathin metal films due to surface roughness [37], [38]. Conventional plasmonic metals like gold, silver, or copper easily react with air or oxygen present in air and humidity and forms compounds. Copper forms oxides in the air [39], [40] and, silver is sensitive to sulfur and forms silver sulfide [41], [42]. As a result of these chemical reactions, they suffer a huge degradation in their optical properties. Besides, metals like gold and silver are not compatible with standard silicon manufacturing processes. Thus, plasmonic devices cannot be manufactured using conventional nanofabrication technologies. They can be diffused into silicon which will alter the optical properties and thus severely degrade the performance of the device [43], [44]. Thus, plasmonic metals like gold and silver are still outside the scope of being manufactured using standard silicon manufacturing technologies and yet to be incorporated in nanoelectronics integrated circuits.

From the models shown by Rakic et al. [29], it has been observed that the dielectric permittivity of metal is a complex parameter. The real part of it accounts for the polarization response, and the imaginary part is responsible for the optical loss. At optical frequencies, the real part of the dielectric permittivity of metal is negative, which is one of the most important plasmonic properties of metals [45]. This negative real part of the permittivity supports the propagation of SPPs at the interface when the material is interacted with light. Thus, researchers are searching for better alternatives which can show similar behavior like metals and will be compatible with traditional nanoelectronic technologies. This paper also reports one of such approaches to use an alternative plasmonic material to form a plasmonic RI sensor with enhanced performance and compatible manufacturing process.

\section{Theoretical model and device design}

\section{(a) Material Selection and Mathematical Model}

To fabricate optical components and integrated circuits, silicon photonics is one of the key technologies nowadays $[39,40]$. It is already being implemented in the commercial-scale [46]. If heavily doped silicon can be used as an alternative to metal, silicon plasmonics has a great possibility in the near future [47]-[49]. Silicon can be doped with arsenic, antimony, phosphorus, etc., group V elements, to make it n-type. It can be doped with group III elements like boron, gallium, aluminum, etc. to make it p-type. Different optical properties of doped silicon have been investigated by Balkanski et al. [50] and Schroder et al. [51]. The solubility of boron, phosphorus, and arsenic impurities in silicon has been investigated by Trumbore [52]. Use of $n$-type silicon would be advantageous because of the smaller effective mass of electrons compared to holes [53] which will require lower doping concentration to 
achieve a negative compared to p-type silicon. Thus, $\mathrm{n}$-doped silicon has been used here as an alternative plasmonic material.

Since plasmonic materials are mainly used for their ability to interact with light, their plasmonic properties can be described by two parameters, dielectric permittivity, $\varepsilon$ and, magnetic permeability $\mu$ [54]. However, at optical frequencies, the permeability value becomes close to unity. Thus, their behavior can adequately be described by the dielectric permittivity only. The frequency-dependent complex dielectric permittivity of highly doped silicon can be described by the Lorentz-Drude model [55].

$$
\varepsilon(\omega)=\varepsilon_{\infty}-\frac{\omega_{p}^{2}}{\omega^{2}\left(1+i \frac{1}{\omega \tau}\right)}
$$

If the real part and imaginary parts are separated, (1) becomes,

$$
\varepsilon(\omega)=\left(\varepsilon_{\infty}-\frac{\omega_{p}^{2} \tau^{2}}{1+\omega^{2} \tau^{2}}\right)+i \frac{\omega_{p}^{2} \tau}{\omega\left(1+\omega^{2} \tau^{2}\right)}
$$

where, $\omega_{p}$ is the plasma frequency, $\varepsilon_{\infty}$ is the infinite frequency relative permittivity or the background permittivity, $\tau$ is the electron/hole relaxation time, $\omega=\frac{2 \pi c}{\lambda}$ is the angular frequency, $c$ is the speed of light in vacuum and $i$ is the imaginary unit. In the case of the highly doped degenerate intrinsic semiconductors $\omega_{p}^{2}=\frac{N e^{2}}{\varepsilon_{0} m_{e f f}}$ and $\tau=\frac{\mu m_{e f f}}{e}$ where, $N$ is the free carrier concentration, $\mu$ is the electron/hole's drift mobility and $m_{\text {eff }}$ is the averaged electron/hole effective mass [56]. Usually, the angular frequency $\omega>>\omega_{p}$ and $\omega_{\tau}>>1$ [61]. Thus, (2) can be rewritten as,

$$
\varepsilon(\omega)=\left(\varepsilon_{\infty}-\frac{\sigma}{\omega^{2} \varepsilon_{0} \tau}\right)+i \frac{\sigma}{\omega^{3} \tau^{2} \varepsilon_{0}}
$$

where, $\sigma \approx e N \mu$ is the conductivity of the doped silicon and $e$ is the charge of an electron and $\varepsilon_{0}$ is the free space permittivity. The infinite frequency relative permittivity or the background permittivity is the high-frequency limiting value that is approximately 11.7 for silicon and is independent of the doping concentration [57], [58]. Here, $\mu=80$ [51] and $m_{\text {eff }}=0.26 * m_{0}$, where, $m_{0}$ is the mass of the electron [59]. The relationship of the real part and imaginary part of the complex dielectric permittivity of n-doped silicon is depicted in Fig 1 which clearly shows that for different wavelengths, after a certain doping concentration the real part of dielectric permittivity becomes negative which is the main requirement to support SPP production and propagation. The refractive index of a material can be calculated using (4).

$$
n \pm i \kappa=\sqrt{\varepsilon(\omega)}
$$

where, $n$ is the real part of the refractive index which indicates the phase velocity and $\kappa$ is the imaginary part of the refractive index which is also called the extinction coefficient. Fig 2 shows the variation of real and imaginary part of refractive index of n-doped silicon with carrier concentration for different wavelengths. 


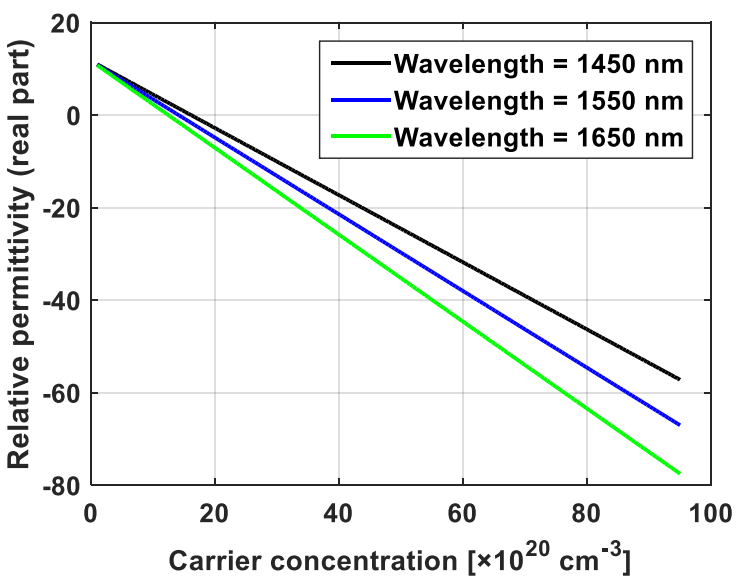

(a)

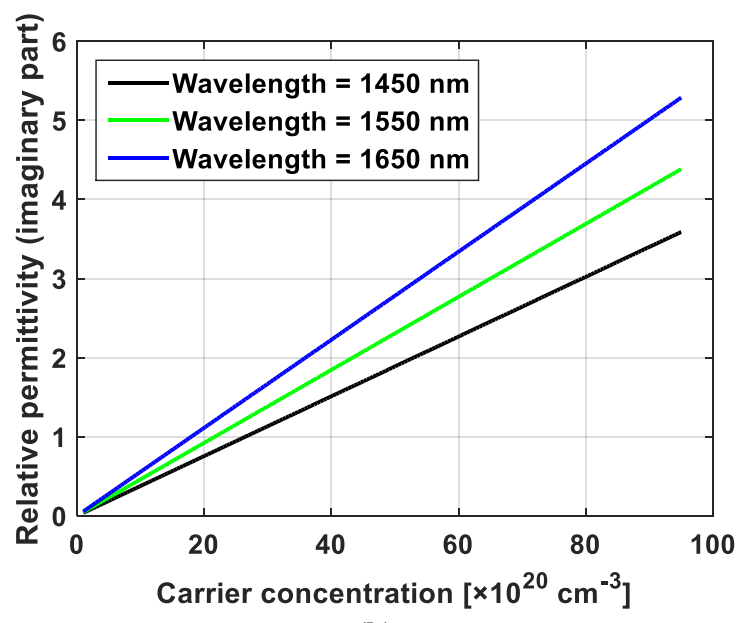

(b)

Fig 1 Relative permittivity (a) real part, (b) imaginary part versus carrier concentration at different wavelengths.

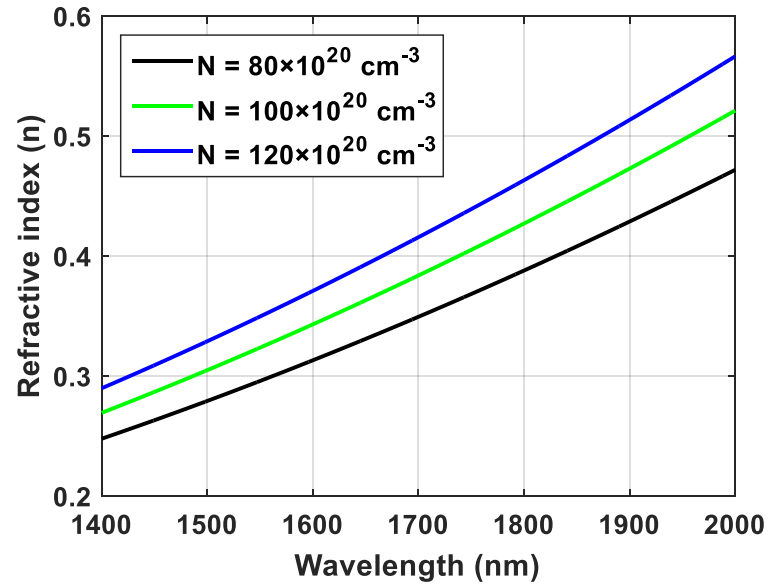

(a)

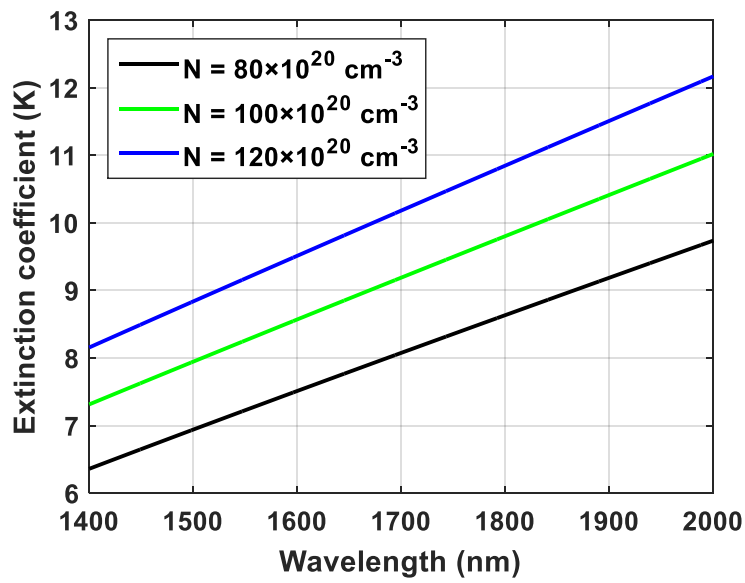

(b)

Fig 2 Refractive index (a) real part, (b) imaginary part versus wavelengths at different carrier concentrations.

\section{(b) Device Design}

The main objectives of the researchers are to improve the sensitivity, Figure of merit (FOM), resolution of the sensor. Some of the already proposed plasmonic sensors have very high sensitivity. Since plasmonic sensors need to be integrated into other optical circuits, one of their main requirements is to be compatible with the optical circuit system where it needs to be integrated. Thus, designing plasmonic sensors with CMOS compatible material like doped silicon may provide a way towards combining conventional electronics and plasmonics. Here, a plasmonic refractive index sensor is designed with CMOS compatible material instead of metal with a very simple ring resonator structure. The sensor has a higher sensitivity compared with the other proposed sensors.

The basic scheme of the plasmonic sensor is composed of a straight waveguide of silicon-air-silicon structure which is connected with a ring cavity inside the silicon layer in which there will be the material under sensing. Fig 3 shows the schematic diagram of the sensor proposed here. The simulation result of this work is simulated in 2D. Most of the proposed plasmonic sensors are also simulated in 2D for an efficient simulation and lower loss [60]. For practical experiments the result will exactly match with $2 \mathrm{D}$ simulation result for the ideal case which is $\mathrm{h}=\infty$. For any height greater than $50 \mathrm{~nm}$, the result will be stable and very close to the simulation result [12]. 


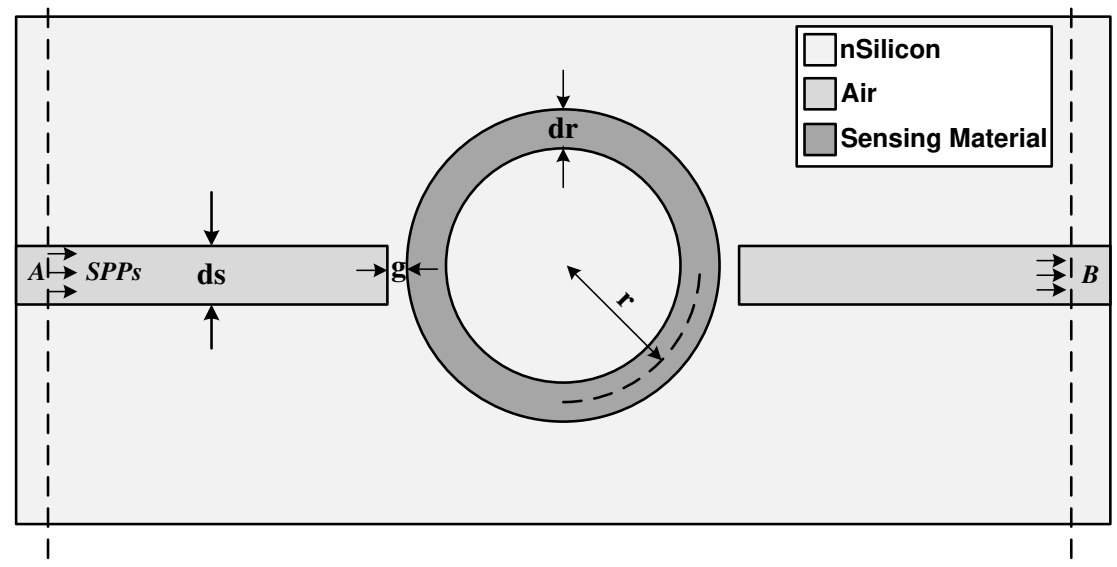

Fig 3 Schematic diagram of the proposed sensor.

\section{Results analysis and discussions}

For the simulation purpose, commercial simulation software COMSOL Multiphysics is used [61]. For numerical analysis, it employs Finite Element Method (FEM) with scattering boundary conditions. To find out the appropriate carrier concentration of $n$-silicon, A straight waveguide is formed with $n$-doped silicon/silver and air interface as shown in Fig 4(a) and simulated to obtain the transmission characteristics. The transmission characteristics obtained for different carrier concentration of $n$-doped silicon is compared with silver-air-silver waveguide of the same structure which is shown in Fig 4(b). The transmittance for the waveguide shown in Fig 4(a) as well as the proposed sensor structure can be obtained by, $T=P_{\text {out }} / P_{\text {in }}$, where, $P_{\text {out }}$ is the output power obtained at port B and $P_{\text {in }}$ is the input power at port $\mathrm{A}$.

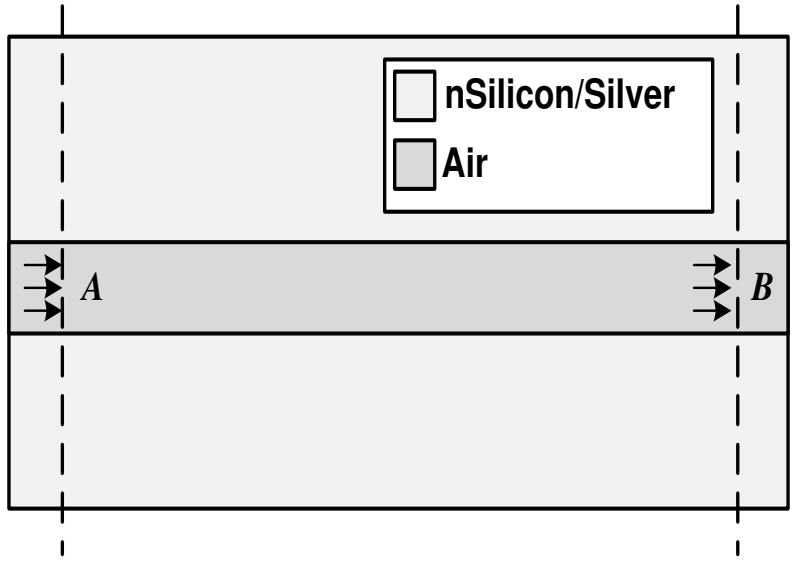

(a)

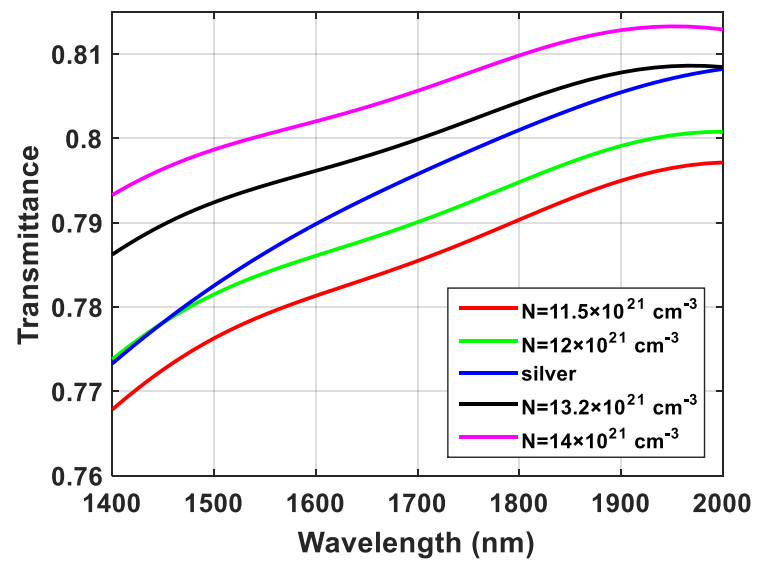

(b)

Fig 4 (a) Silver/n-silicon waveguide, (b) Transmission characteristics shown by the waveguide.

From the transmission characteristics shown in Fig 4(b), it is observed that the transmittance of the waveguide increases with the increase in doping concentration in silicon. However, to achieve higher doping concentration in silicon is still a challenge. To achieve a transmittance more than silver-air-silver waveguide, minimum doping concentration required is $13.2 \times 10^{21} \mathrm{~cm}^{-3}$. The highest doping concentration reported to date is $2 \times 10^{22} \mathrm{~cm}^{-3}$ by Nobili et al. [62] where Arsenic doping is used in silicon. To achieve a better performance than silver-air-silver waveguide devices, a doping concentration of $13.2 \times 10^{21} \mathrm{~cm}^{-3}$ is used here. However, depending on the applications, this doping concentration can be decreased or increased up to maximum reported doping concentration when necessary.

The structure shown in Fig 3 has been investigated here using heavily doped n-type silicon instead of silver which is used is conventional plasmonic devices. The transmission characteristics of the device has been analyzed and tuned 
to obtain a higher sensitivity of the device. The sensitivity, $S$ of the device can be calculated from the resonance peak using the formula,

$$
S=\frac{\Delta \lambda}{\Delta n}
$$

where, $\Delta \lambda$ is the resonance peak shift in $\mathrm{nm}$ and $\Delta n$ is the corresponding refractive index change.

For the structure with typical values i.e. the gap between the ring and straight waveguide, $g=10 \mathrm{~nm}$, the radius of the ring, $\mathrm{r}=170 \mathrm{~nm}$ and, the width of the ring and straight waveguide, $\mathrm{d}=50 \mathrm{~nm}$, the resonance peaks occur at $1573.5 \mathrm{~nm}, 1589 \mathrm{~nm}, 1604.3 \mathrm{~nm}$ and $1619.5 \mathrm{~nm}$ for $\mathrm{n}=1,1.01,1.02$ and 1.03 respectively. The sensitivities obtained are $1550 \mathrm{~nm} / \mathrm{RIU}, 1530 \mathrm{~nm} / \mathrm{RIU}$ and $1520 \mathrm{~nm} / \mathrm{RIU}$, respectively. Thus, a maximum sensitivity of 1550 $\mathrm{nm} / \mathrm{RIU}$ is obtained for the device structure. The transmission characteristics of the device and the resonance shift for different refractive indices have been shown in Fig. 5. Different parameters of the device like the width of the ring, $d r$, the width of the straight waveguide, $d s$; the radius of the ring, $r$ and the gap between the straight waveguide and ring waveguide, $\mathrm{g}$ is then varied to obtain a higher sensitivity.

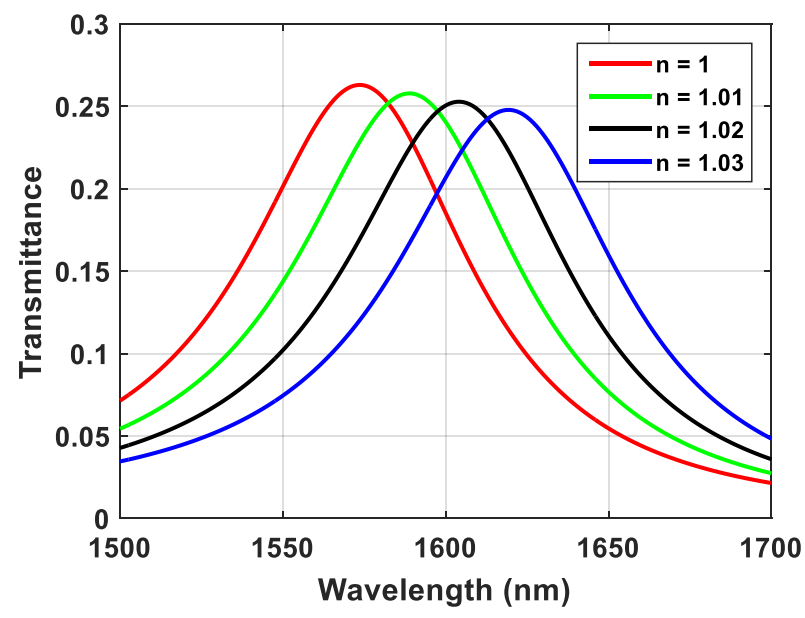

(a)

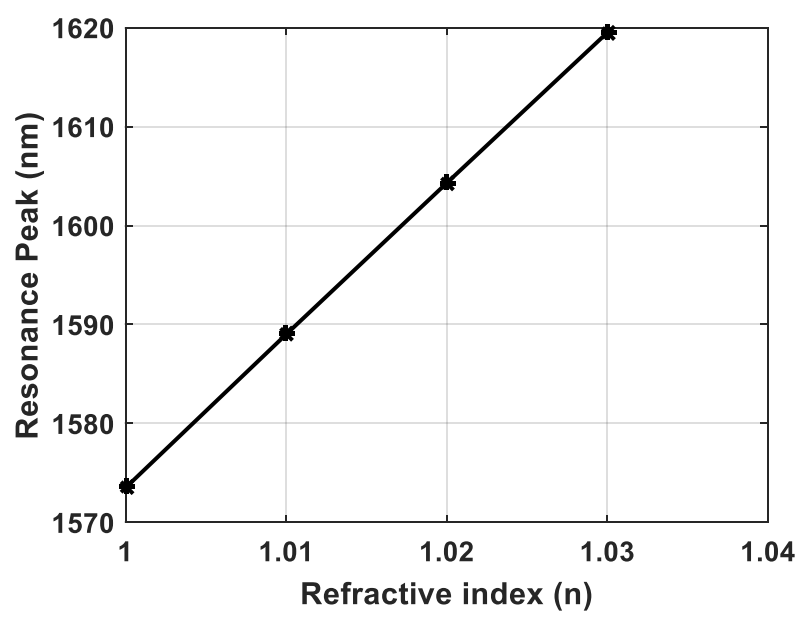

(b)

Fig 5 (a)Transmission characteristics, (b) Resonance Peak shift of the sensor with $\mathrm{g}=10 \mathrm{~nm}, \mathrm{r}=170 \mathrm{~nm}$ and d $=50 \mathrm{~nm}$ for different values of $\mathrm{n}$.

The width of the ring, $\mathrm{dr}$ is varied for getting maximum sensitivity. For $\mathrm{dr}=40 \mathrm{~nm}, 50 \mathrm{~nm}$ and $60 \mathrm{~nm}$, the transmission characteristics are observed for $\mathrm{n}=1$ and $\mathrm{n}=1.01$, which is shown in Fig 6 . The resonance peaks and the sensitivities for different values of $\mathrm{dr}$ are shown in Table 1 and it is observed that the sensitivity increases with the decrease of the radius of the ring. The resonance peaks obtained for $\mathrm{dr}=20 \mathrm{~nm}$ is at $2204 \mathrm{~nm}$, and sensitivity is as high as $4201.9 \mathrm{~nm} / \mathrm{RIU}$.

The width of the straight waveguide, ds is then varied for $n=1$ and $n=1.01$ to obtain the value of ds for maximum sensitivity. The transmission characteristics and the resonance peaks for different values of ds are shown in Fig. 7 and Table 2, respectively. The sensitivity of the device increases with the increase of ds and $\mathrm{ds}=80 \mathrm{~nm}$ is chosen where the sensitivity obtained is $4650 \mathrm{~nm} / \mathrm{RIU}$. The other parameters to choose are the radius of the ring, $\mathrm{r}$ and the gap between the straight waveguide and ring waveguide, $\mathrm{g}$. These parameters are also varied similarly, and the best values of $r$ and $g$ are chosen for best sensitivity. The transmission characteristics with the variation of $r$ and $g$ are shown in Fig. 8 and Fig. 9 respectively. The best value of $r$ is chosen to be $170 \mathrm{~nm}$, and the best value of $g$ is chosen to be $10 \mathrm{~nm}$. With all the suitable values for the sensor as $\mathrm{dr}=20 \mathrm{~nm}$, ds $=80 \mathrm{~nm}, \mathrm{r}=170 \mathrm{~nm}$ and $\mathrm{g}=10 \mathrm{~nm}$, the transmission characteristics are observed for different values of $n$ from 1 to 1.03 with a step of 0.005 . The transmission characteristics for different values of $n$ are shown in Fig. 10. The resonance peaks for different values of $\mathrm{n}$ and sensitivity is shown in Table 3. Fig 11 shows the resonance wavelength shift and sensitivity change with the change of refractive index. From Fig 11(b), it is observed that the sensor shows higher sensitivity for higher values of $n$. Thus, it is possible to obtain much higher sensitivity of the device for sensing liquids whose refractive indices are comparatively higher than gases. 


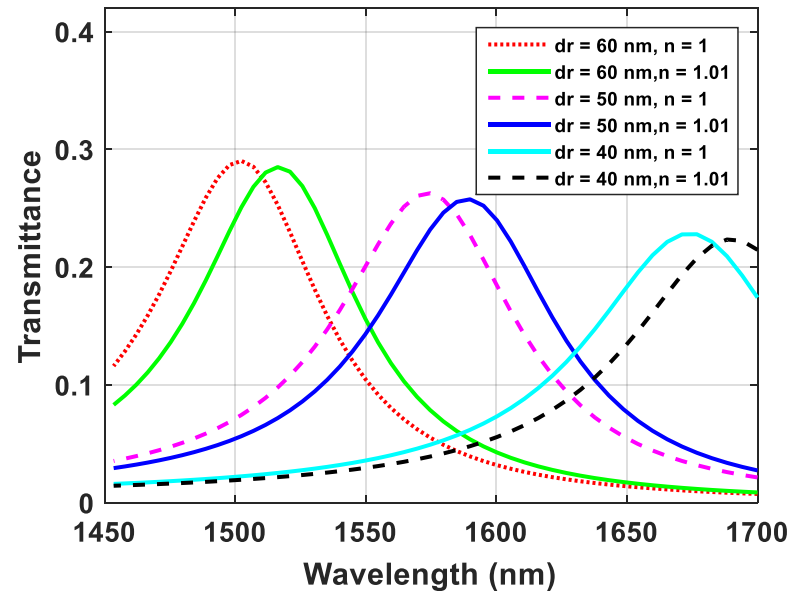

Fig 6 Transmission characteristics of the sensor with $\mathrm{w}=10$ $\mathrm{nm}, \mathrm{r}=170 \mathrm{~nm}$ and $\mathrm{ds}=50 \mathrm{~nm}$ for different values of $\mathrm{dr}$ for $\mathrm{n}$ $=1$ and $\mathrm{n}=1.01$.

Table 1

The resonance peaks and the sensitivities for different values of ring width.

\begin{tabular}{cccc}
\hline $\begin{array}{r}\text { Ring } \\
\text { width, } \\
\mathrm{dr}(\mathrm{nm})\end{array}$ & $\mathrm{n}=1$ & $\mathrm{n}=1.01$ & $\begin{array}{c}\text { Resonsitivity } \\
\text { (nm/RIU) }\end{array}$ \\
\hline \hline 20 & 2204.881 & 2246.9 & 4201.9 \\
30 & 1827.5 & 1844.7 & 1720 \\
40 & 1674.2 & 1689.8 & 1689.8 \\
50 & 1574 & 1589 & 1589 \\
60 & 1501.7 & 1516.05 & 1516.05 \\
\hline \hline
\end{tabular}

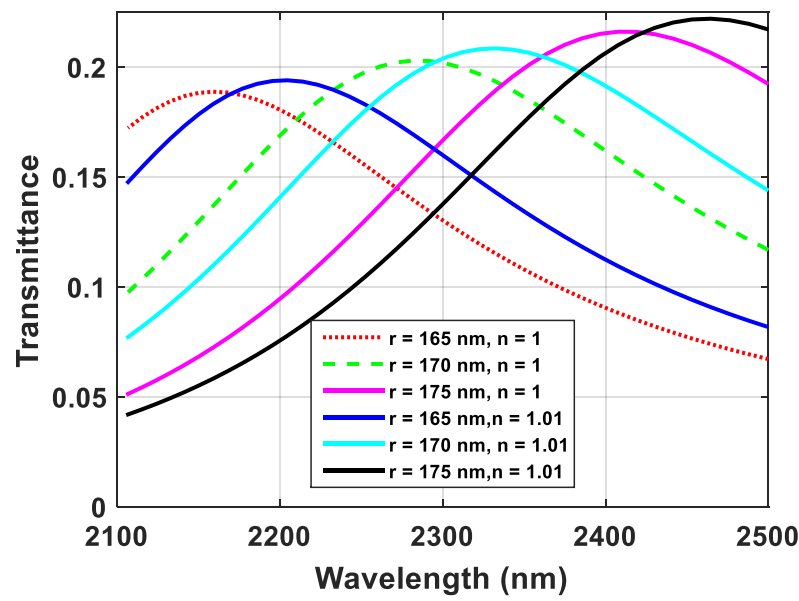

Fig 8 Transmission characteristics of the sensor with $g=10$ $\mathrm{nm}, \mathrm{dr}=20 \mathrm{~nm}$ and $\mathrm{ds}=80 \mathrm{~nm}$ for different values of $\mathrm{r}$ for $\mathrm{n}=$ 1 and $\mathrm{n}=1.01$.

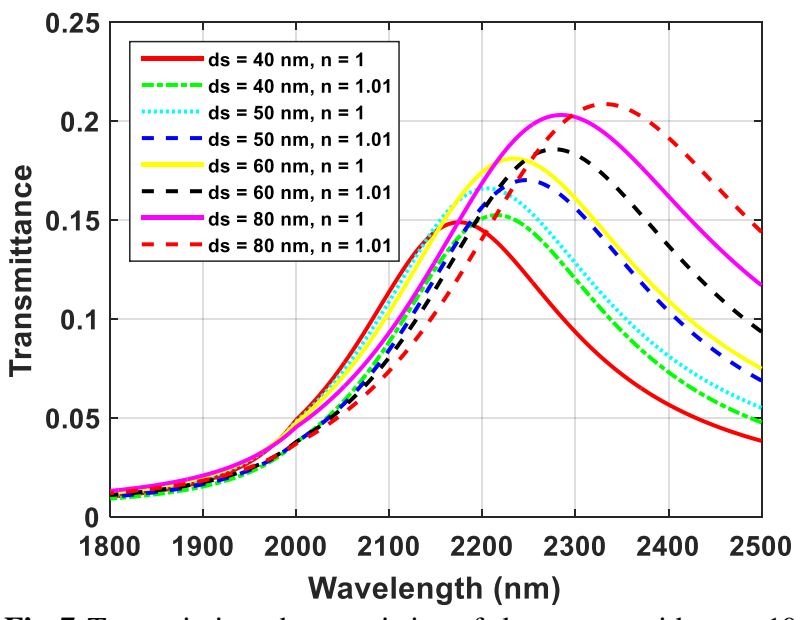

Fig 7 Transmission characteristics of the sensor with $\mathrm{w}=10$ $\mathrm{nm}, \mathrm{r}=170 \mathrm{~nm}$ and different values of $\mathrm{ds}$ for $\mathrm{n}=1$ and $\mathrm{n}=$ 1.01 .

\section{Table 2}

The resonance peaks and the sensitivities for different values of the width of the straight waveguide

\begin{tabular}{cccc}
\hline \hline $\begin{array}{c}\text { Width of the } \\
\text { straight waveguide, } \\
\text { ds (nm) }\end{array}$ & $\mathrm{n}=1$ & $\mathrm{n}=1.01$ & $\begin{array}{c}\text { Rensitivity } \\
\text { (nm/RIU) }\end{array}$ \\
\hline \hline 20 & 2204.881 & 2246.9 & 4201.9 \\
30 & 1827.5 & 1844.7 & 1720 \\
40 & 1674.2 & 1689.8 & 1689.8 \\
50 & 1574 & 1589 & 1589 \\
60 & 1501.7 & 1516.05 & 1516.05 \\
\hline \hline
\end{tabular}

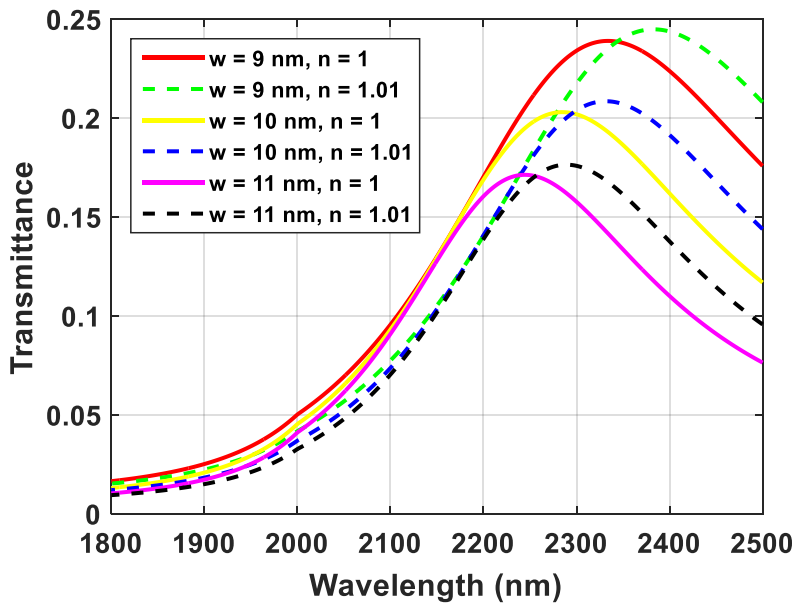

Fig 9 Transmission characteristics of the sensor with ds $=80$ $\mathrm{nm}, \mathrm{r}=170 \mathrm{~nm}$ and different values of $\mathrm{g}$ for $\mathrm{n}=1$ and $\mathrm{n}=$ 1.01 . 


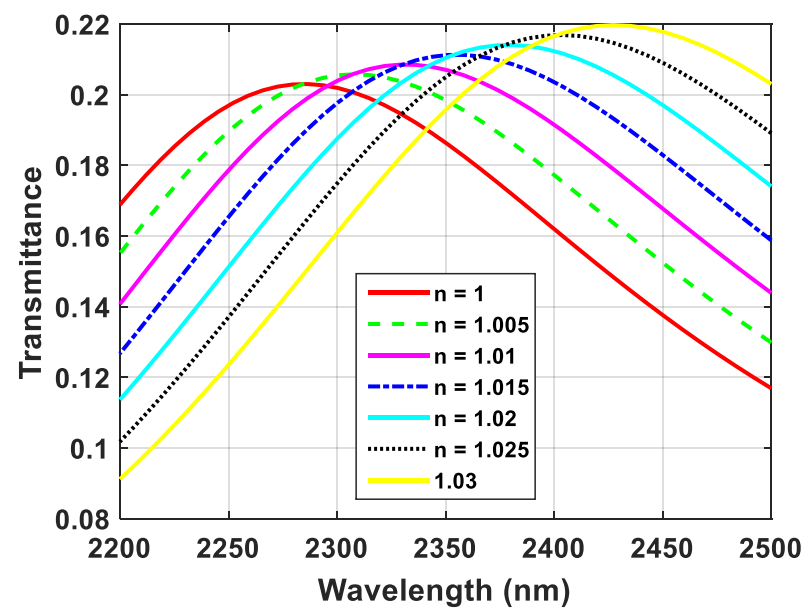

Table 3

Resonance peaks and sensitivities for different values $\mathrm{n}$

\begin{tabular}{ccc}
\hline \hline $\mathrm{n}$ & Resonance peak $(\mathrm{nm})$ & $\begin{array}{c}\text { Sensitivity } \\
(\mathrm{nm} / \mathrm{RIU})\end{array}$ \\
\hline 1 & 2284.9 & ------- \\
1.005 & 2307.94 & 4608 \\
1.01 & 2331.47 & 4706 \\
1.015 & 2355 & 4706 \\
1.02 & 2379 & 4800 \\
1.025 & 2403 & 4800 \\
1.03 & 2427.5 & 4900 \\
\hline \hline
\end{tabular}

Fig 10 Transmission characteristics of the sensor with $\mathrm{ds}=80$ $\mathrm{nm}, \mathrm{r}=170 \mathrm{~nm}$ and $\mathrm{dr}=20 \mathrm{~nm}$ and $\mathrm{w}=10 \mathrm{~nm}$ for different values of $n$.

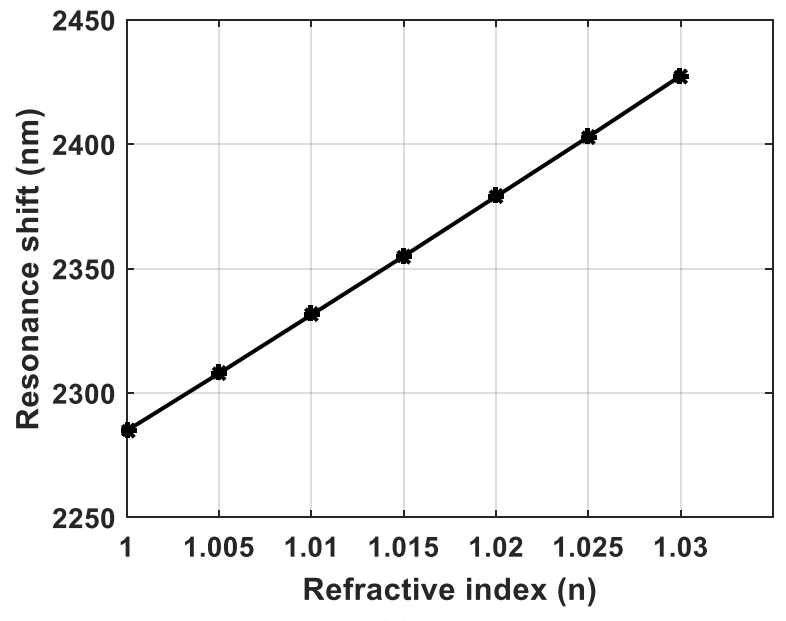

(a)

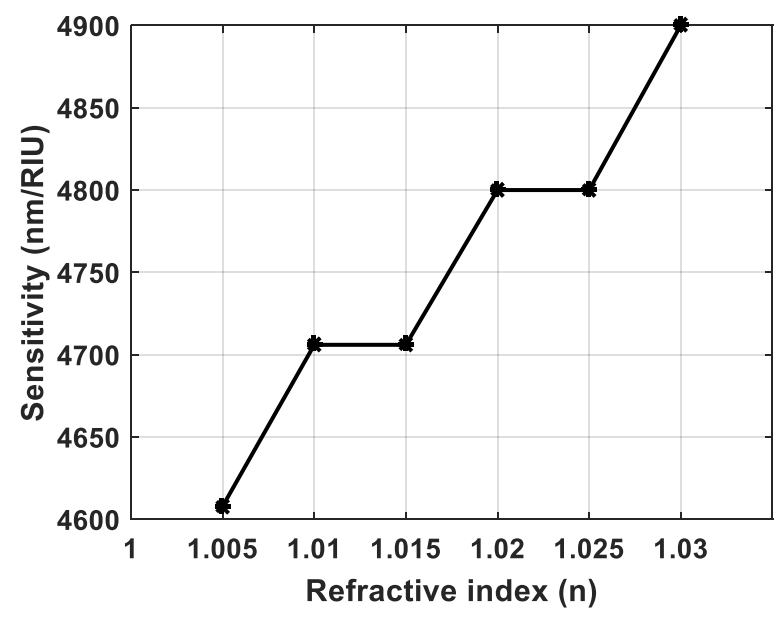

(b)

Fig 11 (a) Resonance shift, (b) Sensitivity variation with refractive index for the proposed sensor.

Table 4

Comparison with other proposed sensors

\begin{tabular}{ccccc}
\hline \hline Proposed Sensor & $\begin{array}{c}\text { Maximum } \\
\text { Sensitivity } \\
\text { (nm/RIU) }\end{array}$ & $\begin{array}{c}\text { Structure } \\
\text { Used }\end{array}$ & $\begin{array}{c}\text { CMOS } \\
\text { Compatibility }\end{array}$ & Year \\
\hline \hline Sensor proposed in this paper & 4900 & Si-I-Si & Yes & 2021 \\
Wu et al. [22] & 3460 & M-I-M & No & 2014 \\
Al Mahmud et al. [63] & 2713 & M-I-M & No & 2021 \\
Al Mahmud et al. [64] & 2325 & M-I-M & No & 2021 \\
Rakhshani et al. [65] & 2320 & M-I-M & No & 2017 \\
Butt et al. [66] & 1367 & M-I-M & No & 2018 \\
Zhang et al. [11] & 1200 & M-I-M & No & 2019 \\
Zhang et al. [12] & 1160 & M-I-M & No & 2018 \\
Butt et al. [13] & 800 & Si and M-I-M & No & 2018 \\
Tu et al. [67] & 363 & Si & Yes & 2017 \\
\hline \hline
\end{tabular}


From Table 3, it is observed that a highest sensitivity of $4900 \mathrm{~nm} / \mathrm{RIU}$ can be obtained for the sensor. Comparison between the other proposed sensor and the sensors proposed is shown in Table 4. Among the other proposed sensors, the sensor proposed by $\mathrm{Wu}$ et al. [51], has the highest sensitivity. However, it was designed using silver as the plasmonic metal which makes it incompatible with CMOS technology. The other proposed sensors have very low sensitivity compared to the sensor proposed here despite using various complex structures. Moreover, they are also not CMOS compatible except the sensor proposed by Tu et al. [70] which has got a very low sensitivity of 363 $\mathrm{nm} / \mathrm{RIU}$ only.

\section{Conclusions}

In order to overcome the limitations of conventional plasmonic metals, the plasmonic properties of an alternative plasmonic material is studied and found to show similar properties like gold and silver. Heavily n-doped silicon can not only replace gold or silver in plasmonic devices but also can enhance the performance of the plasmonic devices to a great extent. The plasmonic sensor studied and tuned here can show a maximum sensitivity of $4900 \mathrm{~nm} / \mathrm{RIU}$, a sensing resolution of $2.041 \times 10^{-4} \mathrm{RIU}$ which is the highest reported till date to the best of our knowledge. Moreover, the all silicon approach used here makes the device compatible with Complementary Metal Oxide Semiconductor (CMOS) technology. This feature enables it to be incorporated in conventional nanoelectronic circuits for on chip sensing applications. The wide sensing range of the device is also suitable for using the device as a gas sensor as well as biosensor.

\section{Funding}

No funding was received for conducting this study.

\section{Conflict of interest/Competing Interests}

On behalf of all authors, the corresponding author states that there is no conflict of interest.

\section{Availability of Data and Material Statement}

Not applicable.

\section{Authors Contributions}

All authors contributed to the study conception and design. Material preparation, data collection and analysis were performed by Md. Omar Faruque, and Rabiul Al Mahmud. The first draft of the manuscript was written by Md. Omar Faruque along with Rakibul Hasan Sagor. All authors commented on previous versions of the manuscript. All authors read and approved the final manuscript.

\section{Code availability}

Not applicable.

\section{Ethical Approval}

Not applicable.

\section{Consent to Participate}

Not applicable.

\section{Consent to Publish}

Not applicable. 


\section{References:}

[1] D. K. Gramotnev and S. I. Bozhevolnyi, "Nanofocusing of electromagnetic radiation," Nat. Photonics, vol. 8, no. 1, p. 13, 2014.

[2] V. A. Zenin et al., "Boosting Local Field Enhancement by on-Chip Nanofocusing and Impedance-Matched Plasmonic Antennas," Nano Lett., vol. 15, no. 12, pp. 8148-8154, 2015, doi: 10.1021/acs.nanolett.5b03593.

[3] W. L. Barnes, A. Dereux, and T. W. Ebbesen, "Surface plasmon subwavelength optics," Nature, vol. 424, no. 6950, p. 824, 2003.

[4] H. Lu, X. Liu, G. Wang, and D. Mao, "Tunable high-channel-count bandpass plasmonic filters based on an analogue of electromagnetically induced transparency," Nanotechnology, vol. 23, no. 44, p. 444003, 2012.

[5] H. Wang et al., "Tunable band-stop plasmonic waveguide filter with symmetrical multiple-teeth-shaped structure," Opt. Lett., vol. 41, no. 6, pp. 1233-1236, 2016.

[6] J. Tian, S. Yu, W. Yan, and M. Qiu, "Broadband high-efficiency surface-plasmon-polariton coupler with silicon-metal interface,” Appl. Phys. Lett., vol. 95, no. 1, p. 13504, 2009.

[7] S. Bahadori-Haghighi, R. Ghayour, and M. H. Sheikhi, "All-Optical Cross-Bar Switch Based on a Low-Loss Suspended Graphene Plasmonic Coupler," Plasmonics, vol. 14, no. 2, pp. 447-456, 2019, doi: 10.1007/s11468-018-0823-2.

[8] N. Gogoi and P. P. Sahu, "All-optical tunable power splitter based on a surface plasmonic two-mode interference waveguide," Appl. Opt., vol. 57, no. 10, pp. 2715-2719, 2018.

[9] N. Nozhat and N. Granpayeh, "Analysis of the plasmonic power splitter and MUX/DEMUX suitable for photonic integrated circuits," Opt. Commun., vol. 284, no. 13, pp. 3449-3455, 2011, doi: 10.1016/j.optcom.2011.03.007.

[10] Y. Guo et al., "A plasmonic splitter based on slot cavity," vol. 19, no. 15, pp. 19091-19096, 2011.

[11] Y. Zhang et al., "High-sensitivity refractive index sensors based on Fano resonance in the plasmonic system of splitting ring cavity-coupled MIM waveguide with tooth cavity," Appl. Phys. A, vol. 125, no. 1, p. 13, 2019.

[12] Z. Zhang et al., "Plasmonic refractive index sensor with high figure of merit based on concentric-rings resonator," Sensors, vol. 18, no. 1, p. 116, 2018.

[13] M. A. Butt, S. N. Khonina, and N. L. Kazanskiy, "Hybrid plasmonic waveguide-assisted Metal-InsulatorMetal ring resonator for refractive index sensing," J. Mod. Opt., vol. 65, no. 9, pp. 1135-1140, 2018.

[14] O. Daneshmandi, A. Alighanbari, and A. Gharavi, "Characteristics of new hybrid plasmonic Bragg reflectors based on sinusoidal and triangular gratings," Plasmonics, vol. 10, no. 1, pp. 233-239, 2015.

[15] A. Hosseini and Y. Massoud, "A low-loss metal-insulator-metal plasmonic bragg reflector," Opt. Express, vol. 14, no. 23, pp. 11318-11323, 2006.

[16] J.-Q. Liu et al., "A wide bandgap plasmonic Bragg reflector,” Opt. Express, vol. 16, no. 7, pp. 4888-4894, 2008.

[17] C. Haffner et al., "All-plasmonic Mach-Zehnder modulator enabling optical high-speed communication at the microscale," Nat. Photonics, vol. 9, no. 8, p. 525, 2015.

[18] Q. Gan, Y. Gao, and F. J. Bartoli, "Vertical Plasmonic Mach-Zehnder interferometer for sensitive optical sensing," vol. 17, no. 23, pp. 2847-2852, 2009.

[19] Y. Gao, Q. Gan, Z. Xin, X. Cheng, and F. J. Bartoli, "Plasmonic Mach-Zehnder interferometer for ultrasensitive on-chip biosensing," ACS Nano, vol. 5, no. 12, pp. 9836-9844, 2011, doi: $10.1021 / \mathrm{nn} 2034204$.

[20] Y. Shen et al., "Plasmonic gold mushroom arrays with refractive index sensing figures of merit approaching the theoretical limit," Nat. Commun., vol. 4, p. 2381, 2013.

[21] H. Wang, "Plasmonic refractive index sensing using strongly coupled metal nanoantennas: nonlocal limitations," Sci. Rep., vol. 8, no. 1, p. 9589, 2018.

[22] T. Wu, Y. Liu, Z. Yu, Y. Peng, C. Shu, and H. Ye, "The sensing characteristics of plasmonic waveguide with a ring resonator," Opt. Express, vol. 22, no. 7, pp. 7669-7677, 2014.

[23] T. Srivastava, R. Das, and R. Jha, "Highly Sensitive Plasmonic Temperature Sensor Based on Photonic Crystal Surface Plasmon Waveguide," Plasmonics, vol. 8, no. 2, pp. 515-521, 2013, doi: 10.1007/s11468012-9421-x.

[24] M. Y. Azab, M. F. O. Hameed, and S. S. A. Obayya, "Temperature Sensors Based on Plasmonic Photonic Crystal Fiber," in Computational Photonic Sensors, Springer, 2019, pp. 179-201.

[25] A. Tittl, H. Giessen, and N. Liu, "Plasmonic gas and chemical sensing," Nanophotonics, vol. 3, no. 3, pp. 157-180, 2014. 
[26] J. M. Bingham, J. N. Anker, L. E. Kreno, and R. P. Van Duyne, "Gas sensing with high-resolution localized surface plasmon resonance spectroscopy," J. Am. Chem. Soc., vol. 132, no. 49, pp. 17358-17359, 2010.

[27] A. G. Brolo, "Plasmonics for future biosensors," Nat. Photonics, vol. 6, no. 11, p. 709, 2012.

[28] W. Law, K. Yong, A. Baev, P. N. Prasad, and L. A. W. E. T. Al, "Sensitivity Improved Surface Plasmon Resonance Biosensor for Cancer Biomarker Detection Based on Plasmonic Enhancement," no. 6, pp. 48584864, 2011.

[29] A. D. Rakić, A. B. Djurišić, J. M. Elazar, and M. L. Majewski, "Optical properties of metallic films for vertical-cavity optoelectronic devices," Appl. Opt., vol. 37, no. 22, p. 5271, 1998, doi: 10.1364/ao.37.005271.

[30] J. B. Khurgin and A. Boltasseva, "Reflecting upon the losses in plasmonics and metamaterials," MRS Bull., vol. 37, no. 8, pp. 768-779, 2012, doi: 10.1557/mrs.2012.173.

[31] W. Cai, U. K. Chettiar, A. V Kildishev, and V. M. Shalaev, "Optical cloaking with metamaterials," Nat. Photonics, vol. 1, no. 4, p. 224, 2007.

[32] R. W. Cohen, G. D. Cody, M. D. Coutts, and B. Abeles, "Optical properties of granular silver and gold films," Phys. Rev. B, vol. 8, no. 8, p. 3689, 1973.

[33] Y. Yagil and G. Deutscher, "Transmittance of thin metal films near the percolation threshold," Thin Solid Films, vol. 152, no. 3, pp. 465-471, 1987.

[34] F. Abelès, Y. Borensztein, and T. López-Rios, "Optical properties of discontinuous thin films and rough surfaces of silver," in Advances in Solid State Physics, Springer, 1984, pp. 93-117.

[35] K. Fuchs, "The conductivity of thin metallic films according to the electron theory of metals," in Mathematical Proceedings of the Cambridge Philosophical Society, 1938, vol. 34, no. 1, pp. 100-108.

[36] F. Warkusz, "Electrical and mechanical properties of thin metal films: size effects," Prog. Surf. Sci., vol. 10, no. 3, pp. 287-382, 1980.

[37] E. Kretschmann, "Decay of non radiative surface plasmons into light on rough silver films. Comparison of experimental and theoretical results," Opt. Commun., vol. 6, no. 2, pp. 185-187, 1972.

[38] D.-L. Hornauer, "Light scattering experiments on silver films of different roughness using surface plasmon excitation," Opt. Commun., vol. 16, no. 1, pp. 76-79, 1976.

[39] W. E. Campbell and U. B. Thomas, "Films on freshly abraded copper surfaces [7]," Nature, vol. 142, no. 3588, pp. 253-254, 1938, doi: 10.1038/142253b0.

[40] G. H. Chan, J. Zhao, E. M. Hicks, G. C. Schatz, and R. P. Van Duyne, "Plasmonic properties of copper nanoparticles fabricated by nanosphere lithography," Nano Lett., vol. 7, no. 7, pp. 1947-1952, 2007.

[41] H. E. Bennett, R. L. Peck, D. K. Burge, and J. M. Bennett, "Formation and growth of tarnish on evaporated silver films," J. Appl. Phys., vol. 40, no. 8, pp. 3351-3360, 1969, doi: 10.1063/1.1658187.

[42] D. K. Burge, J. M. Bennett, R. L. Peck, and H. E. Bennett, "Growth of surface films on silver," Surf. Sci., vol. 16, pp. 303-320, 1969.

[43] G. Bemski, "Recombination properties of gold in silicon," Phys. Rev., vol. 111, no. 6, p. 1515, 1958.

[44] L. D. Yau and C. T. Sah, "Measurement of trapped-minority-carrier thermal emission rates from Au, Ag, and Co traps in silicon," Appl. Phys. Lett., vol. 21, no. 4, pp. 157-158, 1972.

[45] E. D. Palik, Handbook of Optical Constants of Solids, Five-Volume Set: Handbook of Thermo-Optic Coefficients of Optical Materials with Applications. Elsevier, 1997.

[46] R. Soref, L. Fellow, and I. Paper, "The Past, Present, and Future of Silicon Photonics," vol. 12, no. 6, pp. 1678-1687, 2006.

[47] J. A. Dionne, L. A. Sweatlock, M. T. Sheldon, A. P. Alivisatos, and H. A. Atwater, "Silicon-based plasmonics for on-chip photonics," IEEE J. Sel. Top. quantum Electron., vol. 16, no. 1, pp. 295-306, 2010.

[48] A. Hryciw, Y. C. Jun, and M. L. Brongersma, "Plasmonics: Electrifying plasmonics on silicon," Nat. Mater., vol. 9, no. 1, p. 3, 2010.

[49] R. Soref, "Mid-infrared photonics in silicon and germanium," Nat. Photonics, vol. 4, no. 8, p. 495, 2010.

[50] M. Balkanski, A. Aziza, and E. Amzallag, "Infrared Absorption in Heavily Doped n-Type Si," Phys. status solidi, vol. 31, no. 1, pp. 323-330, 1969.

[51] D. K. Schroder, R. N. Thomas, and J. C. Swartz, "Free carrier absorption in silicon," IEEE J. Solid-State Circuits, vol. 13, no. 1, pp. 180-187, 1978.

[52] F. A. Trumbore, "Solid solubilities of impurity elements in germanium and silicon," Bell Syst. Tech. J., vol. 39, no. 1, pp. 205-233, 1960.

[53] H. D. Barber, "Effective mass and intrinsic concentration in silicon," Solid. State. Electron., vol. 10, no. 11, pp. 1039-1051, 1967.

[54] L. D. Landau, J. S. Bell, M. J. Kearsley, L. P. Pitaevskii, E. M. Lifshitz, and J. B. Sykes, Electrodynamics of 
continuous media, vol. 8. elsevier, 2013.

[55] S. A. Maier, Plasmonics: fundamentals and applications. Springer Science \& Business Media, 2007.

[56] M. G. Saber, N. Abadía, and D. V Plant, "CMOS compatible all-silicon TM pass polarizer based on highly doped silicon waveguide," Opt. Express, vol. 26, no. 16, pp. 20878-20887, 2018.

[57] G. V Naik, V. M. Shalaev, and A. Boltasseva, "Alternative plasmonic materials: beyond gold and silver," Adv. Mater., vol. 25, no. 24, pp. 3264-3294, 2013.

[58] Y.-B. Chen and Z. M. Zhang, "Heavily doped silicon complex gratings as wavelength-selective absorbing surfaces,” J. Phys. D. Appl. Phys., vol. 41, no. 9, p. 95406, 2008.

[59] M. Van Exter and D. Grischkowsky, "Carrier dynamics of electrons and holes in moderately doped silicon," Phys. Rev. B, vol. 41, no. 17, p. 12140, 1990.

[60] S. Naghizadeh and Ş. E. Kocabaş, "Guidelines for designing 2D and 3D plasmonic stub resonators," J. Opt. Soc. Am. B, vol. 34, no. 1, p. 207, 2017, doi: 10.1364/josab.34.000207.

[61] A. B. Comsol, "COMSOL multiphysics user's guide," Version Sept., vol. 10, p. 333, 2005.

[62] D. Nobili, S. Solmi, A. Parisini, M. Derdour, A. Armigliato, and L. Moro, "Precipitation, aggregation, and diffusion in heavily arsenic-doped silicon," Phys. Rev. B, vol. 49, no. 4, p. 2477, 1994.

[63] R. Al Mahmud, M. O. Faruque, and R. H. Sagor, "A highly sensitive plasmonic refractive index sensor based on triangular resonator," Opt. Commun., vol. 483, p. 126634, Mar. 2021, doi: 10.1016/j.optcom.2020.126634.

[64] R. Al Mahmud, M. O. Faruque, and R. H. Sagor, "Plasmonic Refractive Index Sensor Based on Ring-Type Pentagonal Resonator with High Sensitivity," Plasmonics, 2021, doi: 10.1007/s11468-020-01357-7.

[65] M. R. Rakhshani and M. A. Mansouri-Birjandi, "High sensitivity plasmonic refractive index sensing and its application for human blood group identification," Sensors Actuators, B Chem., vol. 249, pp. 168-176, Oct. 2017, doi: 10.1016/j.snb.2017.04.064.

[66] M. A. Butt, S. N. Khonina, and N. L. Kazanskiy, "Plasmonic refractive index sensor based on metalinsulator-metal waveguides with high sensitivity," J. Mod. Opt., vol. 66, no. 9, pp. 1038-1043, May 2019, doi: 10.1080/09500340.2019.1601272.

[67] Z. Tu, D. Gao, M. Zhang, and D. Zhang, "High-sensitivity complex refractive index sensing based on Fano resonance in the subwavelength grating waveguide micro-ring resonator," Opt. Express, vol. 25, no. 17, pp. 20911-20922, 2017. 
Figures

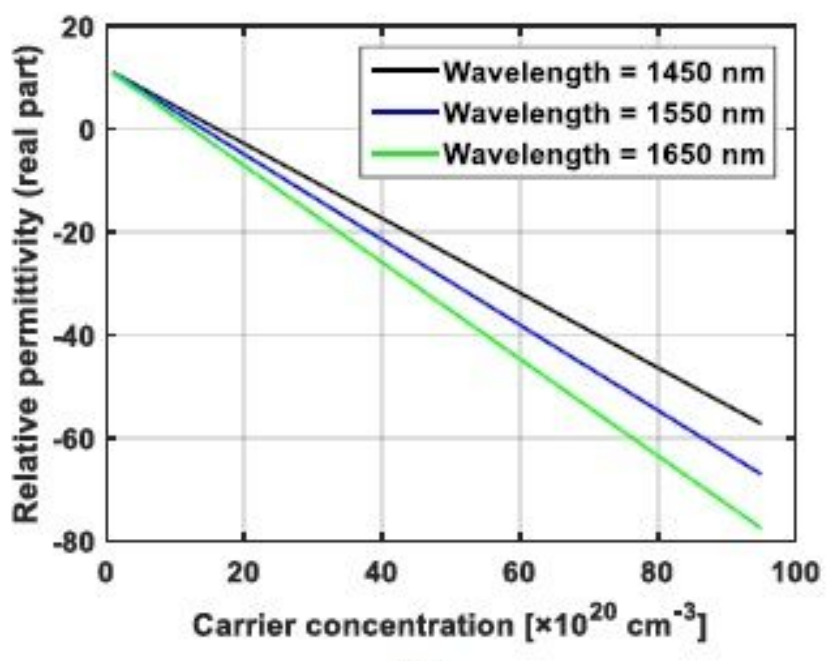

(a)

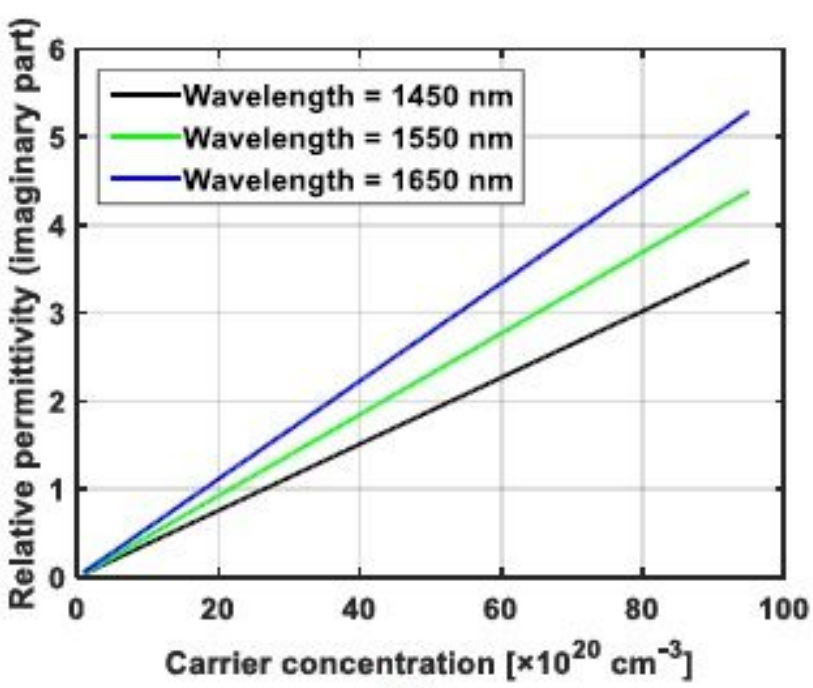

(b)

\section{Figure 1}

Relative permittivity (a) real part, (b) imaginary part versus carrier concentration at different wavelengths.

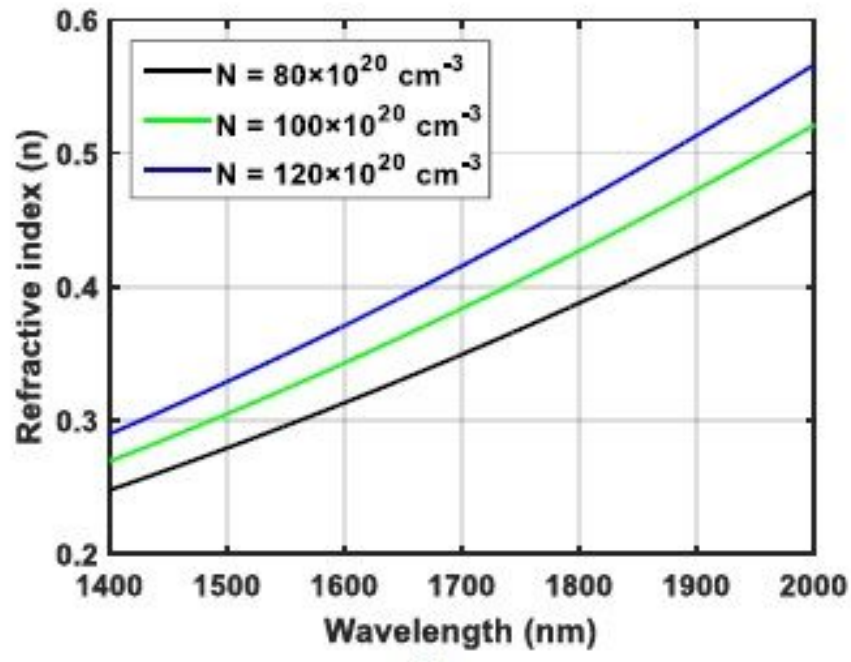

(a)

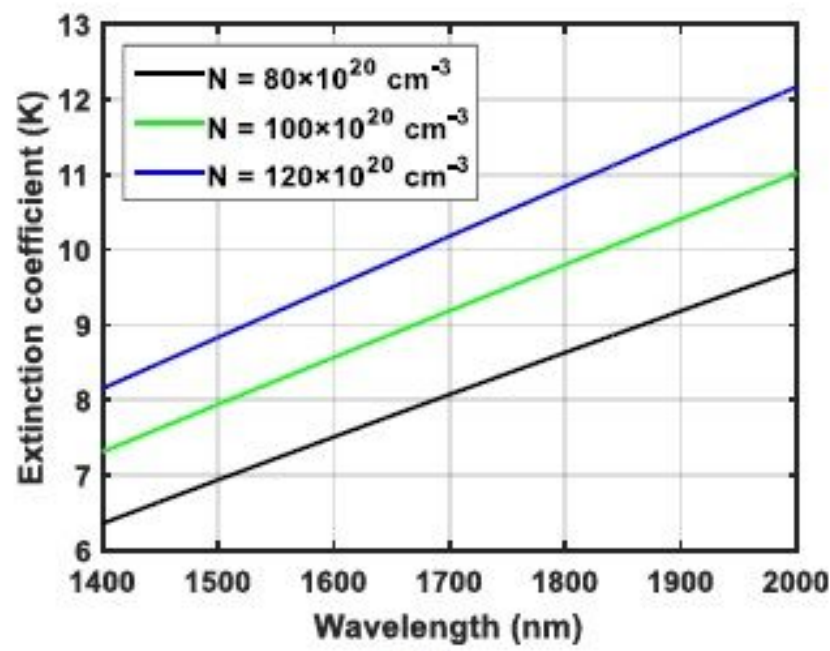

(b)

Figure 2

Refractive index (a) real part, (b) imaginary part versus wavelengths at different carrier concentrations. 


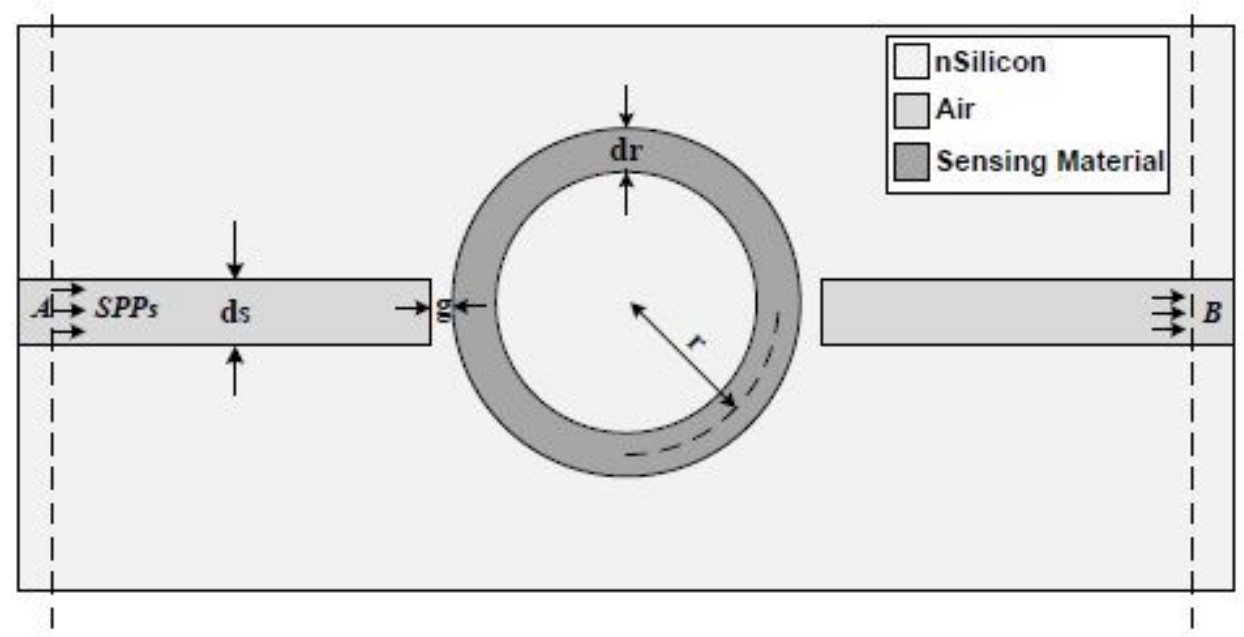

Figure 3

Schematic diagram of the proposed sensor.

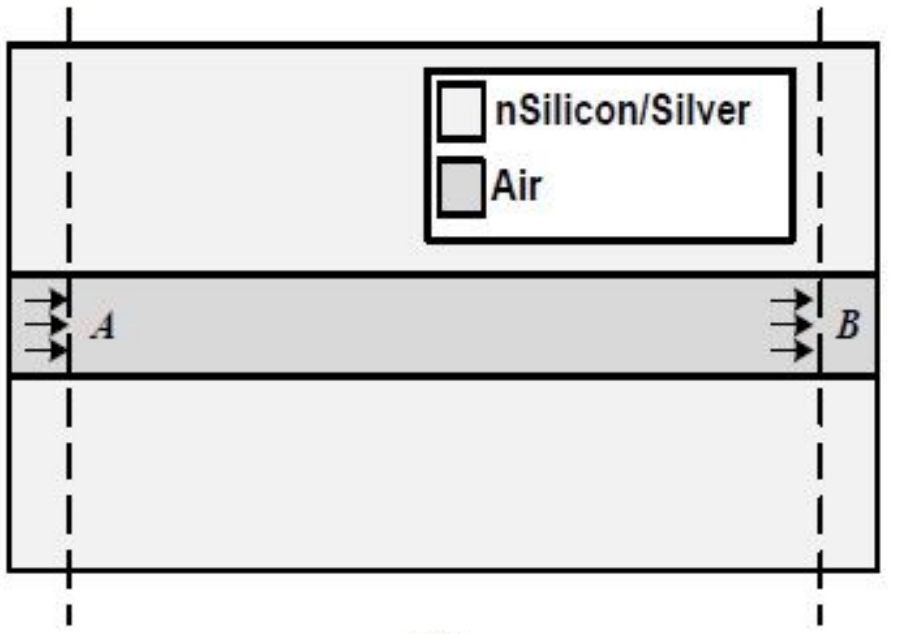

(a)

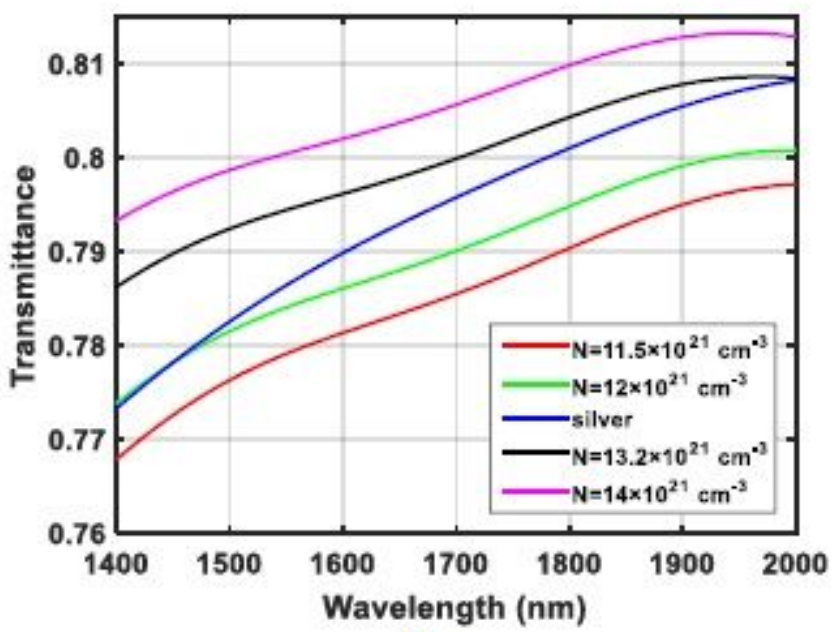

(b)

Figure 4

(a) Silver/n-silicon waveguide, (b) Transmission characteristics shown by the waveguide. 


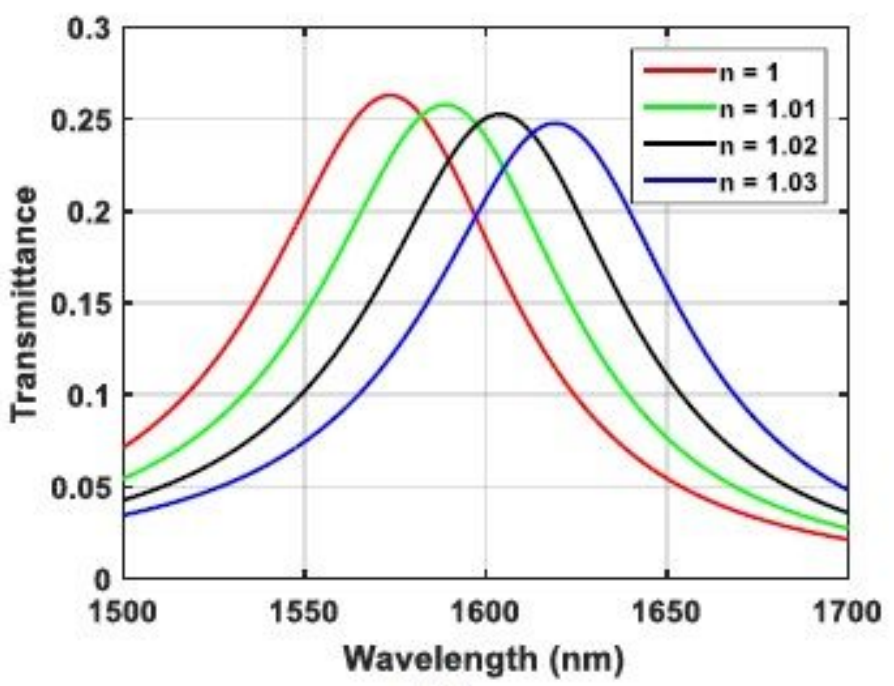

(a)

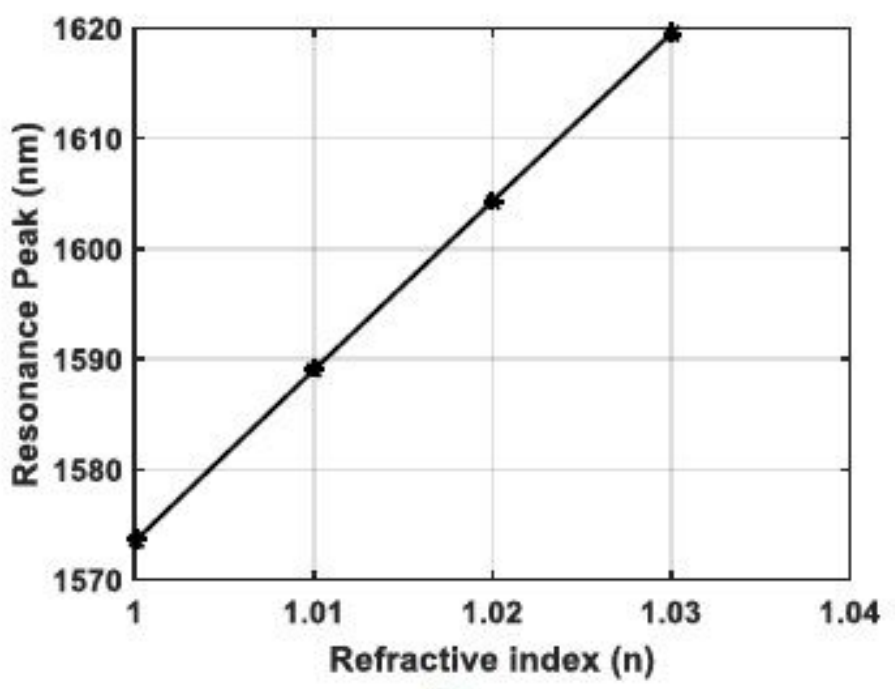

(b)

\section{Figure 5}

(a)Transmission characteristics, (b) Resonance Peak shift of the sensor with $\mathrm{g}=10 \mathrm{~nm}, \mathrm{r}=170 \mathrm{~nm}$ and d $=50 \mathrm{~nm}$ for different values of $\mathrm{n}$.

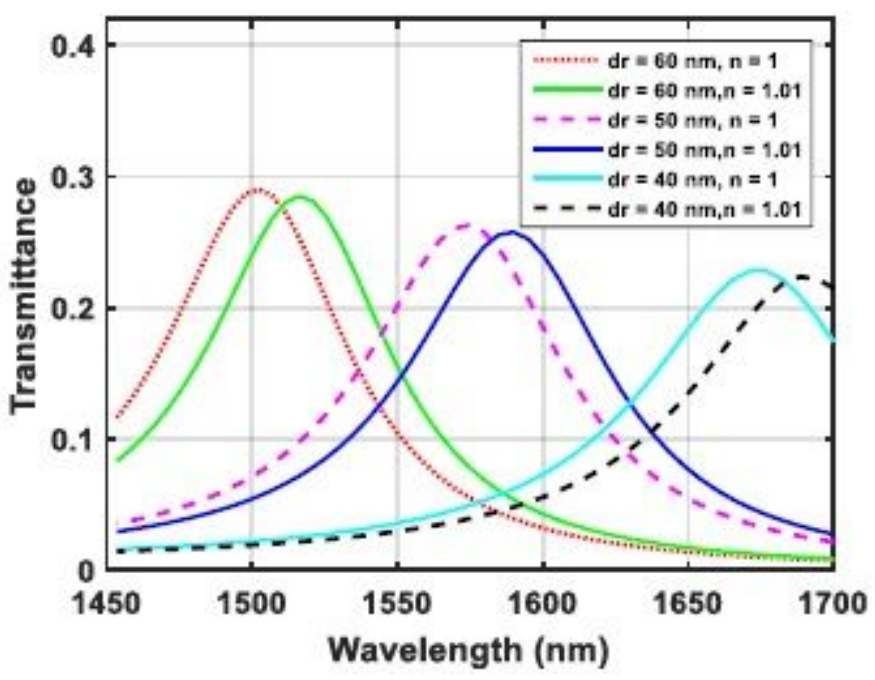

\section{Figure 6}

Transmission characteristics of the sensor with $w=10 \mathrm{~nm}, r=170 \mathrm{~nm}$ and $\mathrm{ds}=50 \mathrm{~nm}$ for different values of $\mathrm{dr}$ for $\mathrm{n}=1$ and $\mathrm{n}=1.01$. 


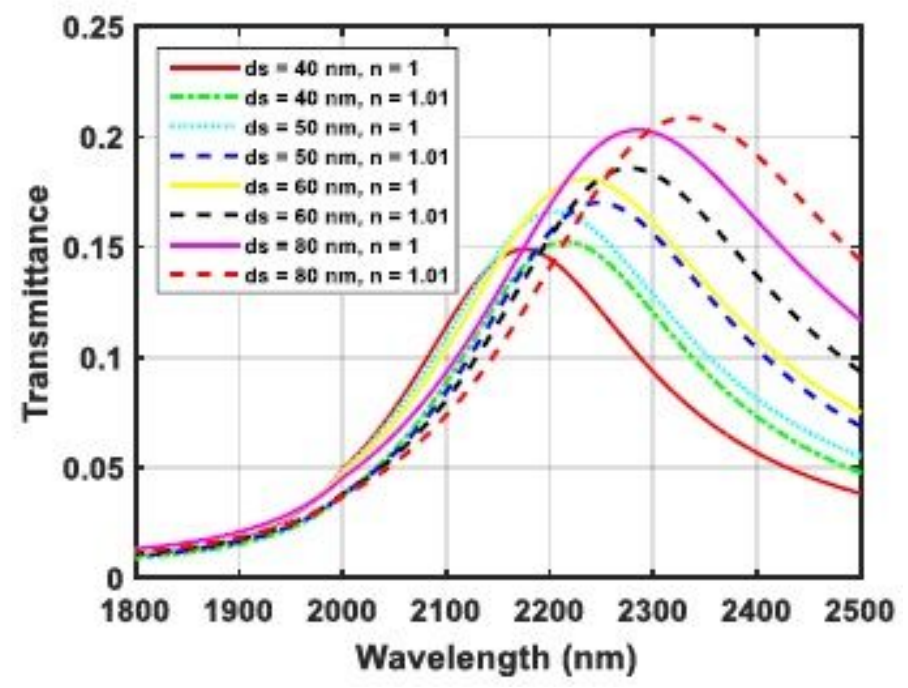

Figure 7

Transmission characteristics of the sensor with $w=10 \mathrm{~nm}, \mathrm{r}=170 \mathrm{~nm}$ and different values of ds for $\mathrm{n}=1$ and $\mathrm{n}=1.01$.

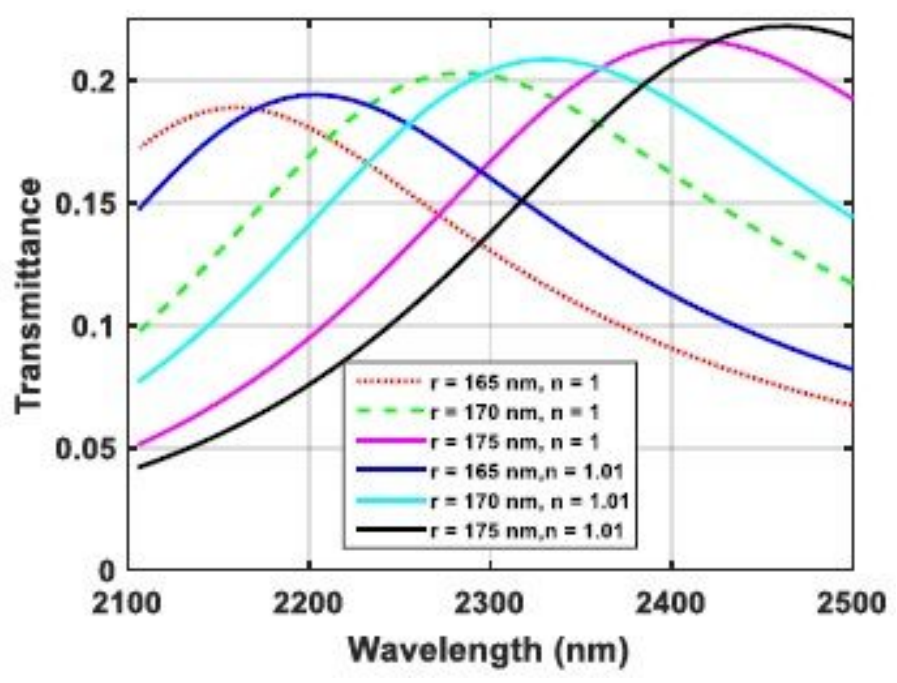

Figure 8

Transmission characteristics of the sensor with $\mathrm{g}=10 \mathrm{~nm}, \mathrm{dr}=20 \mathrm{~nm}$ and $\mathrm{ds}=80 \mathrm{~nm}$ for different values of $r$ for $n=1$ and $n=1.01$. 


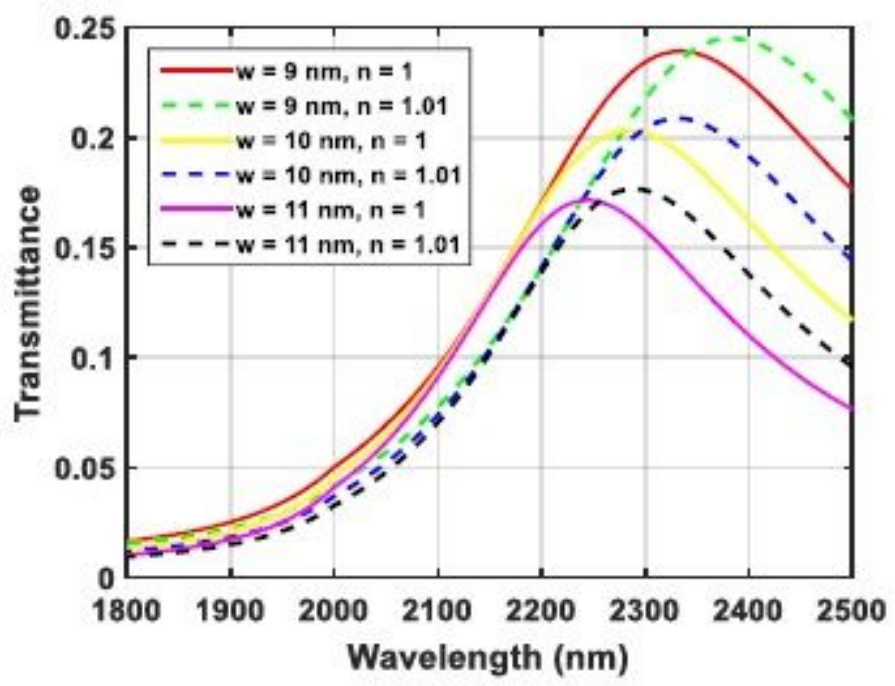

Figure 9

Transmission characteristics of the sensor with $\mathrm{ds}=80 \mathrm{~nm}, \mathrm{r}=170 \mathrm{~nm}$ and different values of $\mathrm{g}$ for $\mathrm{n}=1$ and $\mathrm{n}=1.01$.

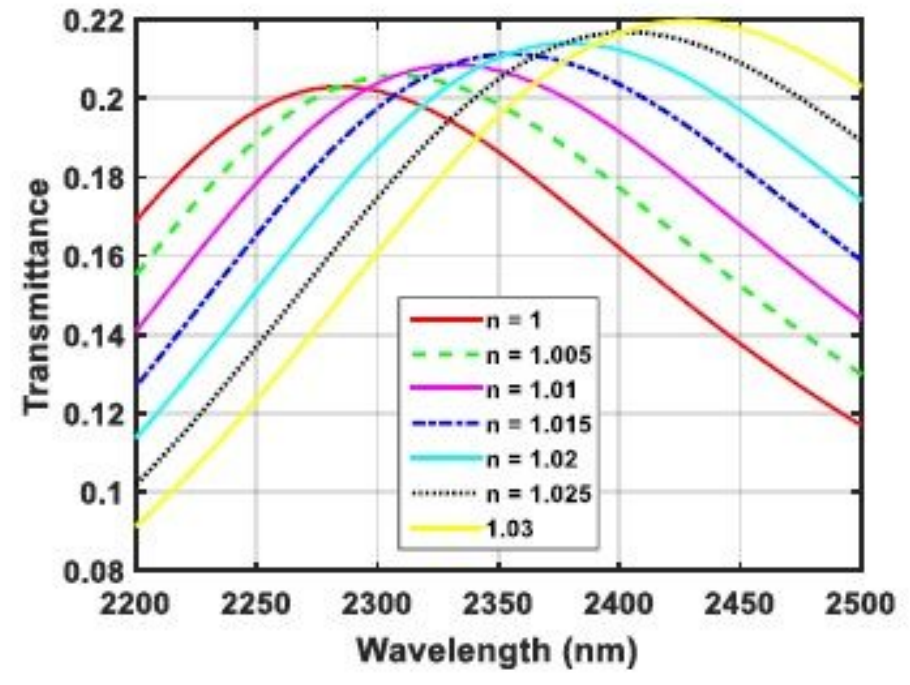

Figure 10

Transmission characteristics of the sensor with ds $=80 \mathrm{~nm}, \mathrm{r}=170 \mathrm{~nm}$ and $\mathrm{dr}=20 \mathrm{~nm}$ and $\mathrm{w}=10 \mathrm{~nm}$ for different values of $n$. 


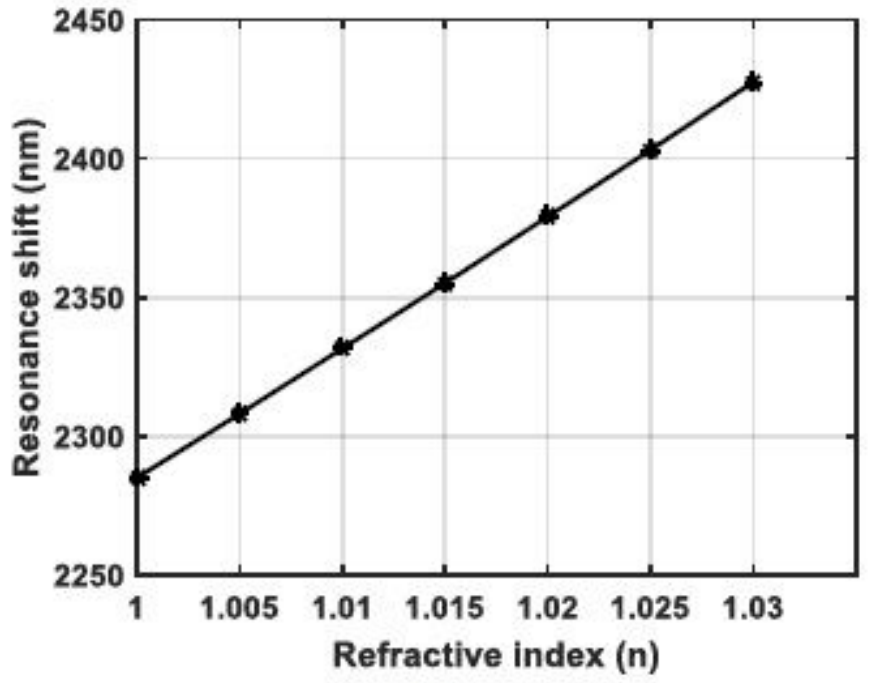

(a)

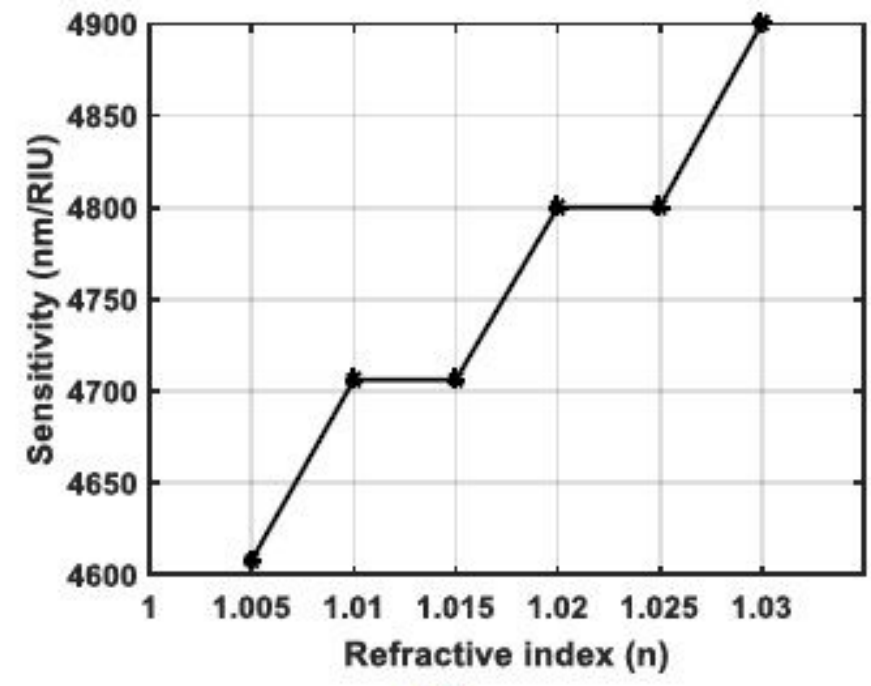

(b)

Figure 11

(a) Resonance shift, (b) Sensitivity variation with refractive index for the proposed sensor. 